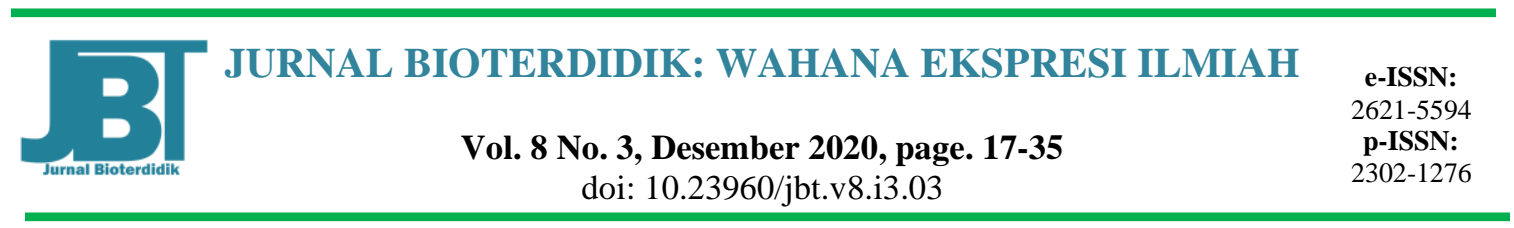

\title{
Pengaruh Lingkungan dan Elevasi Terhadap Kualitas Fitokimia dan Cita Rasa Kopi Robusta Muria Kudus
}

\author{
Ahmad Fauzan Hidayatullah \\ Pendidikan Biologi, Fakultas Sains dan Teknologi, Universitas Islam Negeri Walisongo Semarang, \\ Indonesia, Jl. Walisongo No.3-5, Tambakaji, Kec. Ngaliyan, Kota Semarang, Jawa Tengah \\ e-mail: afhidayatullah@walisongo.ac.id
}

Received: December 14, 2020

Accepted: December 30, 2020

Online Published: December 30, 2020

\begin{abstract}
The Influence of Environment and Elevation on Phytochemical Quality and Taste of Muria Kudus Robusta Coffee. Factors that affect quality and taste, one of which is the elevation (height) of coffee plants. This factor is an external factor that is hardlined. The best way is to plant coffee at the most suitable elevation and post-harvest processing. The aim of the study was to see an increase in coffee content and the roasting component of organoleptic coffee. Research uses survey methods and to use Microsoft Excel. This research was conducted at Mount Muria Kudus. The elevation carried out in this study is 400-600 masl, 800-1,000 masl, 1,200 masl and> 1,200 masl. The paramaeter observed included the content of antioxidants, ash, air, fat, caffeine and organoleptics which included color, texture, aroma, and taste. The results showed that for Muria Robusta coffee, the higher the elevation the higher the antioxidant content, caffeine and water content, while at the ash and maximum levels at an altitude of 800-1.00 masl and fat content at an altitude of 1,200 masl.
\end{abstract}

Keywords: elevation, chemical content, organoleptic, robusta coffee

Abstrak: Pengaruh Lingkungan dan Elevasi Terhadap Kualitas Fitokimia dan Cita Rasa Kopi Robusta Muria Kudus. Faktor yang mempengaruhi mutu dan citarasa, salah satunya adalah elevasi (ketinggian) tanaman kopi. Faktor ini merupakan faktor eksternal yang sukar dimodifikasi. Cara paling tepat adalah menanam kopi pada elevasi yang paling cocok dan pengolahan pasca panen. Tujuan penelitian adalah untuk melihat pengaruh elevasi terhadap kandungan kimia kopi dan pengaruh penyangraian terhadap organoleptik kopi. Penelitian menggunakan metode survei dan untuk perhitungan hasilnya menggunakan bantuan Microsoft excel. Penelitian ini dilakukan di Gunung Muria Kudus Elevasi yang digunakan pada penelitian ini adalah 400-600 mdpl, 800-1.000 mdpl, 1.200 mdpl dan > 1.200 mdpl. Parameter yang diamati meliputi kandungan antioksidan, abu, air, lemak, kafein dan organoleptik yang meliputi warna, tekstur, aroma, dan rasa. Hasil penelitian menunjukkan bahwa kopi Robusta Muria, semakin tinggi elevasi maka kandungan antioksidan, kafein, dan kadar airnya terus meningkat, sedangkan pada kadar abu nilai maksimum pada ketinggian 800-1.000 mdpl dan kandungan lemak pada ketinggian 1.200 mdpl.

Kata kunci: elevasi, kandungan kimia. kopi robusta, organoleptik 


\section{PENDAHULUAN}

Kopi (Coffea sp.) termasuk salah satu komoditas perkebunan yang memiliki nilai ekonomis cukup tinggi diantara tanaman perkebunan lainnya dan berperan penting sebagai sumber devisa negara. Data menunjukkan, pada tahun 2015 Indonesia mengekspor kopi ke berbagai negara senilai US\$1.197.735, sedang untuk catatan impor hanya senilai US\$ 31.492 (Direktorat Jenderal Perkebunan, 2016). Kopi tidak hanya berperan penting dalam menyumbang devisa negara melainkan juga merupakan sumber penghasilan berharga bagi petani kopi di Indonesia.

Keberhasilan agribisnis kopi tidak terlepas dari dukungan berbagai pihak. Dukungan itu, tercermin dalam proses produksi kopi, pengolahan, sampai pemasaran komoditas kopi. Upaya meningkatkan produktivitas dan mutu kopi terus menerus dilakukan sehingga daya saing kopi di Indonesia dapat bersaing di pasar dunia. Mutu dan citarasa adalah aspek yang diandalkan, sehingga sasaran akhir budidaya kopi adalah produk biji yang berkualitas, penghasil kopi seduh yang mantap dan disukai konsumen.

Faktor yang mempengaruhi mutu dan citarasa, salah satunya adalah elevasi (ketinggian) tanaman kopi. Faktor ini merupakan faktor eksternal yang sukar dimodifikasi. Cara paling tepat adalah menanam kopi pada elevasi yang paling cocok. Pengolahan pasca panen menjadi penentu selanjutnya, pada tahap ini biji kopi di fermentasi, dicuci, dipilah-pilah menurut jenis, dikeringkan, dan disangrai demi terciptanya biji kopi berkualitas.

Luas lahan perkebunan kopi di Indonesia mencapai 1.230.001 hektar dan 899.627 hektar $(73,14 \%)$ di antaranya merupakan perkebunan kopi Robusta (Direktorat Jenderal Perkebunan, 2016). Kopi Robusta lebih lebih tahan terhadap hama dibanding dengan kopi Arabika. Tak heran bila kopi ini sekitar $73,14 \%$ diminati petani untuk ditanam diperkebunannya.

Kondisi lingkungan tumbuh kopi Robusta di setiap daerah produksi beragam sehingga menghasilkan mutu dan citarasa yang berbeda antara satu dengan lainnya (Soetriono, 2009). Pada umumnya kopi dengan ketinggian lebih, mempunyai pertumbuhan yang relatif lambat sehingga tekstur kopi semakin padat. Hal tersebut yang menjadi dasar di adakannya penelitian mengenai kandungan kimia kopi Robusta pada masing-masing ketinggian yang berbeda.

Di Jawa Tengah ada beberapa perkebunan kopi yang sudah merajai pasar dunia salah satunya adalah kopi di lereng Muria-Lingkungan tumbuh kopi Muria berdampingan dengan tanaman padi dan jagung. Pengolahan kopi Robusta di tempat tersebut umumnya menggunakan pengolahan basah. Pengolahan basah lebih dipilih disebabkan oleh biaya pengolahan yang lebih murah dibanding dengan pengolahan kering. Dalam pemanenan biji kopi sebagian besar masih serampangan, seringkali biji kopi petik merah tercampur dengan biji kopi berwarna hijau dan kuning.

Tujuan penelitian ini adalah unuk mengetahui bagaimana pengaruh dari elevasi terhadap kandungan kimia dan cita rasa pada kopi yang berada di Lereng Muria dengan parameter yang digunakan berupa kafein, kadar abu, kadar lemak dan kadar air.

\section{METODE}

Kopi merupakan tanaman perkebunan yang memiliki potensi keberhasilan agribisnis di Indonesia. Produktivitas dan mutu kopi dipengaruhi oleh elevasi (ketinggian) dan pengolahan (proses rosting). Adapun lokasi pengambilan sampel dari Gunung Muria meliputi Muria 400-600 mdpl, Muria 800-1000 mdpl, Muria 1200 mdpl, 
dan Muria 1200++ mdpl. Penulis melakukan uji kandungan kimia untuk mengetahui pengaruh elevasi terhadap kandungan kimia pada kopi di Lereng Muria.

Uji kandungan kimia meliputi uji kadar air dengan metode gravimetri oven, uji kadar abu melalui metode gravimetri furnace, uji kadar lemak menggunakan metode soxlet, uji aktivitas antioksidan menggunakan metode DPPH (kristal 1,1 -difenil-2pikrilhidrazil), dan uji kadar kafein dengan metode HPLC (High Performance Liquid Chromatography). Hasil yang diperoleh dari uji kandungan senyawa kimia dan uji organoleptik diolah dan dianalisis_dan dikaitkan dengan literatur terkait guna penarikan kesimpulan oleh penulis.

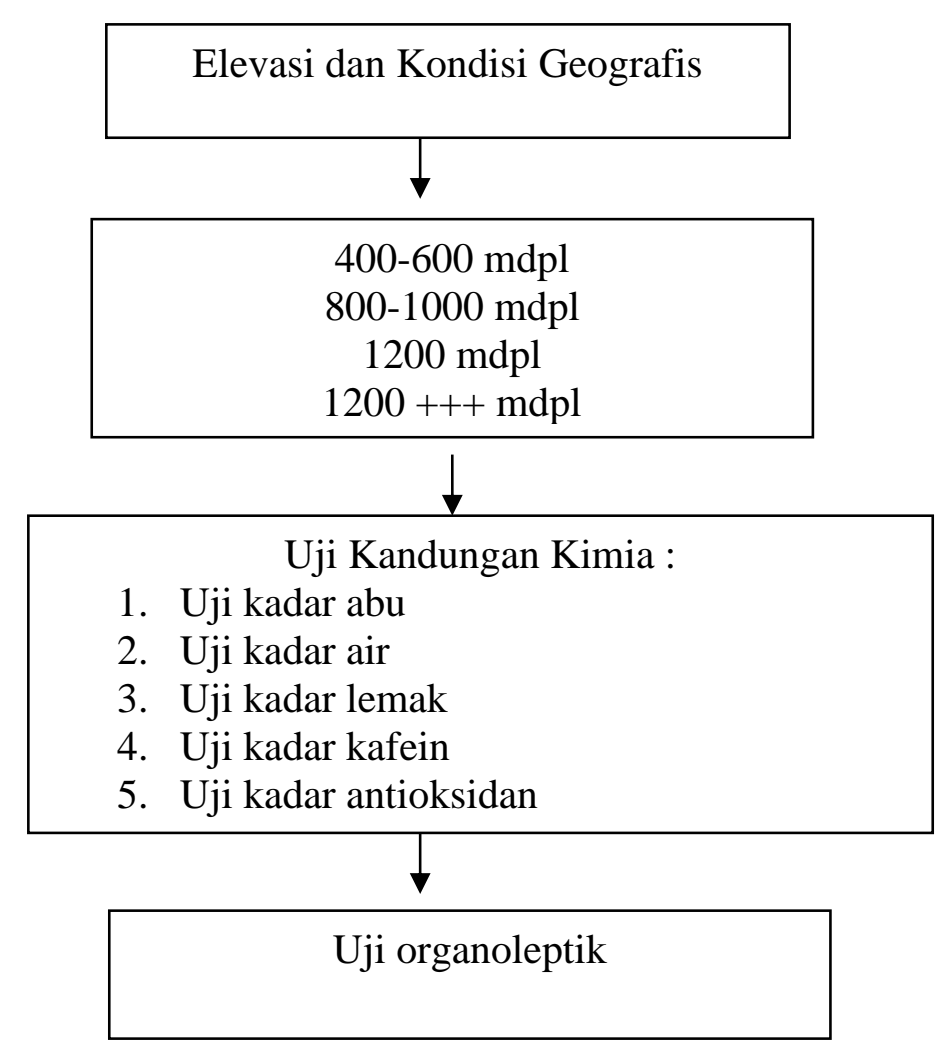

Gambar 1. Bagan rancangan penelitian

Sampel yang digunakan adalah biji kopi yang diolah menjadi serbuk kopi. Teknik pengambilan sampel menggunakan Probability Sampling dengan jenis Proportionate Stratified Random Sampling merupakan teknik yang digunakan apabila populasi memiliki anggota atau unsur yang tidak homogen dan berstrata secara proporsional. Sampel kopi diambil berdasarkan ketinggian lokasi, di Gunung Muria. Terdapat empat sampel yang diamati diantaranya adalah Kopi Muria Robusta dengan ketinggian 400-600 mdpl, Kopi Muria Robusta 800-1000 mdpl, Kopi Muria Robusta 1200 mdpl, Kopi Muria Robusta 1200++ mdpl. Sampel diambil secara acak dan berstrata. Masing-masing sampel pada setiap uji dilakukan dengan tiga kali ulangan untuk meminimalisir human error baik determinate error maupun indeterminate error.

Teknik pengumpulan data melalui observasi yaitu pengamatan dan pencatatan secara sistematik terhadap gejala yang tampak pada objek penelitian. Observasi menjadi salah satu teknik pengumpulan data menggunakan pengamatan terhaadap objek penelitian yang dilaksanakan secara langsung maupun tidak langsung (Tanzeh, 2009). 
Studi pustaka juga dilakukan untuk menunjang dalam penyusunan laporan penelitian ini melalui buku-buku, jurnal, artikel dari internet, hasil penelitian dan surat kabar.

Penelitian ini dibagi menjadi beberapa tahap. Tahap pertama adalah pengumpulan sampel yang mulai dilaksanakan pada bulan November 2017 sampai bulan Maret 2018. Biji kopi sebagai sampel yang diambil di Lereng Muria dan Lereng Sindoro. Tahap kedua adalah proses pengolahan biji kopi yang dilakukan mulai pada bulan April 2018 sampai bulan Juli 2018. Tahap ketiga merupakan tahap uji kandungan senyawa pada bubuk kopi dimulai bulan Agustus sampai September 2018 di Laboratorium Terpadu Teknik Pangan Universitas Sorgijapranata Semarang.

Teknik analisis data berdasarkan pola yang terbentuk dari masing-masing uji. Penggunaan perangkat lunak (software) Microsoft excel digunakan untuk mempermudah pembacaan hasil. alat-alatnya terdiri dari neraca analitik, oven pembakar, cawan petri dan kertas penyaring, tabung reaksi, vortex, mixer spuit, corong penyaring dan labu ukur. Dan bahan yang diperlukan adalah bubuk kopi muria, air serta alkohol.

Prosedur penelitian adalah survei dengan penetapan pohon contoh dilakukan dengan cara purposiive, dengan kriteria keseragaman tumbuh dan jumlah dompolan seragam. Analisis data mengikuti Rancangan Acak Lengkap (RAL) dengan dua faktor dan tiga ulangan. Faktor pertama adalah empat ketinggian tempat, yaitu $400 \mathrm{mdpl}, 600$ mdpl, 800 mdpl, 1000 mdpl. Faktor kedua adalah teknik pengolahan buah kopi, yaitu basah dan kering. Teknik pengolahan basah dan kering yang dilakukan mengacu kepada Prastowo (2010) dan Widyotomo (2012).

Uji kandungan senyawa pada kopi dengan ketinggian tertentu melalui berbagai tahap:

Uji kadar air dengan metode gravimetri (oven). Cawan kosong dipanaskan dalam oven pada temperature $105^{\circ} \mathrm{C}$ selama 30 menit. Selanjutnya didinginkan dalam eksikator selama 15 menit. Kemudian ditimbang $\left(\mathrm{W}_{0}\right)$. Kemudian sampel sebanyak 2 gram dimasukkan pada cawan yang telah diketahui beratnya. Ditimbang $\left(\mathrm{W}_{1}\right)$ lalu dikeringkan dalam oven pada suhu $105^{\circ} \mathrm{C}$ selama 3 jam. Selanjutnya didinginkan dalam eksikator selama 15-30 menit. Kemudian cawan dan isinya ditimbang dan dikeringkan kembali selama 1 jam serta didinginkan di dalam eksikator, ditimbang kembali $\left(\mathrm{W}_{2}\right)$. Kandungan air dihitung dengan rumus:

$$
\text { Kadar air }(\%)=\frac{\left(W_{1}-W_{2}\right)}{\left(W_{1}-W_{0}\right)} \times 100
$$

Keterangan:

$\mathrm{W}_{0}=$ berat cawan kosong

$\mathrm{W}_{1}=$ berat cawan + sampel awal (sebelum pemanasan dalam oven)

$\mathrm{W}_{2}=$ berat cawan + sampel awal (setelah pendinginan dalam eksikator)

Uji kadar abu dengan metode gravimetri (furnace). Masing-masing sampel kopi ditimbang sebanyak 5 gram. Ulangan dilakukan sebanyak tiga kali. Selanjutnya diabukan dengan furnace pada suhu $500^{\circ} \mathrm{C}$ dengan wadah porselen selama 1 jam. Selanjutnya ditimbang hingga berat yang didapatkan tetap dan selanjutnya dihitung persentase kadar abu yang terbentuk dari sampel kopi. 
Uji lemak dengan metode soxlet. Uji Soxhlet memiliki prinsip ekstrksi lemak dengan pelarut lemak seperti petroleum benzena, petroleum eter, aseton, dan lainnya. Berat lemak kemudian ditentukan dengan cara memisahkan lemak dengan pelarutnya (Asmariani, 2017). Masing-masing sampel sebanyak 5 gram ditimbang dan dimasukkan ke dalam selongsong kertas yang disumbat dengan kertas penyaring. Kemudian sampel dimasukkan ke dalam soxhlet yang dihubungkan dengan labu lemak berisi batu didih yang telah dikeringkan dan diketahui bobotnya. Sampel diekstraksi menggunakan heksana (selama kurang lebih 6 jam), kemudian heksana disulingkan dan ekstrak lemak dikeringkan dalam oven pengering pada suhu $105^{\circ} \mathrm{C}$. Ekstrak lemak didinginkan dan ditimbang (pengeringan diulangi hingga tercaapai bobot tetap). Kadar emak dihitung menggunakan persamaan berikut:

$$
\text { Kadar Lemak }(\%)=\frac{W_{2}-W_{1}}{W} \times 100 \%
$$

Keterangan :

$\mathrm{W}=$ bobot contoh $(\mathrm{g})$

$\mathrm{W}_{1}=$ bobot labu sebelum ekstraksi (g)

$\mathrm{W}_{2}=$ bobot labu sesudah ekstraksi $(\mathrm{g})$

Uji aktivitas antioksidan dengan metodr DPPH. Uji antioksidan diawali dengan membuat ekstrak kopi yang dilarutkan dengan alkohol. Uji aktivitas antioksidan penangkap radikal ekstrak metanol dilaakukan dengan metode DPPH. Selanjutnya diinkubasi pada suhu kamar selama 30 menit di tempat yang gelap. Selanjutnya larutan tersebut diukur absorbansinya menggunakan spektrofotometer. Data hasil pengukuran absorbansi dianalisa persentase aktivitas antioksidannya menggunakan persamaan berikut ini:

$$
\begin{gathered}
\% \text { Inhibisi }=\frac{A_{\text {blanko }}-A_{\text {sampel }}}{A_{\text {blanko }}} \times 100 \% \\
\text { Keterangan : } \\
\text { A }=\text { Nilai absorbansi }
\end{gathered}
$$

Uji kafein dengan metode HPLC. Uji HPLC (High Performance Liquid Chromatograaphy) merupakan metode kromatografi cair bertekanan tinggi. Prinsip kerja HPLC berdasarkan distribusi komponen-komponen diantara dua fasa yang disebabkan oleh perbedaan kepolaran. Prinsip kerja alat instrument HPLC adalah dengan bantuan pompa, fasa gerak cair dialirkan melalui kolom disikator. Selanjutnya cuplikan dimasukkan ke dalam aliran fasa gerak dengan cara penyuntikan. Di dalam kolom terjadi pemisahan komponen-komponen campuran.

Perbedaan kekuatan interaksi antara solute-solute terhadap fasa diam. Solute-solute yang kurang kuat interaksinya dengan fasa diam maka solute-solute tersebut akan keluar dari kolom lebih lama. Setiap komponen campuran yang keluar kolom dideteksi oleh detector kemudian direkam dalam bentuk kromatogram.

\section{HASIL DAN PEMBAHASAN}

Hasil uji kandungan senyawa dapat dilihat pada Tabel 1 yang menunjukkan bahwa adanya pengaruh elevasi terhadap kandungan antioksidan biji Kopi Robusta Muria Kudus. Nilai tengah pengaruh elevasi berkisar antara 23,99 \% - 29,33\%. Elevasi 400-600 mdpl menunjukkan nilai tengah kadar antioksidan terendah, sedangkan elevasi 1200++ mdpl menunjukkan nilai tengah kadar antioksidan tertinggi. Elevasi berbanding lurus dengan kadar antoiksidan biji Kopi Robusta Muria Kudus. Semakin tinggi elevasi maka 
antioksidan yang dikandung oleh biji Kopi semakin tinggi pula. Rata-rata kenaikan setiap elevasi adalah $1.78 \%$. Tabel 1 juga menunjukkan bahwa elevasi memiliki pengaruh terhadap kadar antioksidan pada biji Kopi Robusta Muria . Berdasarkan table 1 dapat dilihat bahwa kenaikan antioksidan memiliki batas elevasi, dan setelah batas elevasi tersebut terlampaui maka kadar antioksidan pada biji Kopi Robusta muria akan kembali turun. Kadar antioksidan terendah berada pada elevasi tertinggi yaitu 1200++mdpl, sednagkan kadar antioksidan tertinggi berada pada elevasi 1200 mdpl. Pada ketinggian terendah kadar antioksidan sebesar 24,62\% kemudian kenaikan elevasi selanjutnya yaitu pada elevasi 600-800 mdpl menunjukkan kenaikan kadar antioksidan sebesar 4,42\%, kemudian pada ketinggian 1200 mdpl mengalami kenaikan sebesar 1,43\%, tetapi pada ketinggian $1200++$ mdpl mengalami penurunan kadar antioksidan yang sangat signifikan yaitu sebesar $11.33 \%$.

Tabel 1. Hasil uji kadar senyawa dalam sampel kopi

\begin{tabular}{|l|l|l|l|l|l|}
\hline \multirow{2}{*}{ Sampel } & \multicolumn{5}{|c|}{ Uji } \\
\cline { 2 - 6 } & Antioksidan & Air & Abu & lemak & kafein \\
\hline $\begin{array}{l}\text { Muria 400- } \\
600 \text { mdpl }\end{array}$ & $23,99 \%$ & 0,8 & $2,16 \%$ & $10,08 \%$ & $1,12 \%$ \\
\hline $\begin{array}{l}\text { Muria 800- } \\
1000 \text { mdpl }\end{array}$ & $26,52 \%$ & 0,9 & $2,46 \%$ & $10,08 \%$ & $1,45 \%$ \\
\hline $\begin{array}{l}\text { Muria } \\
\begin{array}{l}1000-1200 \\
\text { mdpl }\end{array}\end{array}$ & $27,32 \%$ & 1,2 & $2,40 \%$ & $10,37 \%$ & $1,95 \%$ \\
\hline $\begin{array}{l}\text { Muria } \\
1200+++\end{array}$ & $29,37 \%$ & $8 \%$ & & & \\
\hline
\end{tabular}

Kadar air pada biji kopi mulai berkurang saat pengeringan, kemudian berkurang kembali saat memasuki proses penyangraian. Kadar air pada kopi yang telah menjadi bubuk berkisar 4-5.4\% (Syah, H, Y Yusmanizar, dan Maulana, O., 2013). Hasil pengukuran terhadap kadar air yang terkandung dalam biji kopi Robusta Muria Kudus dapat dilihat pada tabel 1. Dari tabel tersebut dapat dilihat bahwa kadar air kopi Robusta Muria Kudus terus mengalami peningkatan yang bertahap seiring dengan kenaikan elevasi lokasi penanaman. Kadar airnya berkisar antara 0,85 \% - 2,11\%. Kenaikan kadar air signifikan ditunjukkan pada elevasi $1.200++$ mdpl, pada elevasi sebelumnya kadar air yang dikandung sebanyak 1,28 \% kemudian mencapai peningkatan menjadi 2,11\%.

Berdasarkan Tabel 1 dapat dilihat bahwa kopi Robusta Muria Kudus memiliki kadar abu pada biji kopinya yang berbeda-beda berdasraran tingkat elevasinya. Kandungan kadar abu pada kopi Robusta Muria Kudus menunjukkan bahwa semakin tinggi elevasinya semakin rendah kadar abunya. Dimulai pada elvasi 400-600 mdpl yang memiliki kadar abu sebanyak 2,16 \%, kemudian pada elevasi selanjutnya mengalami kenaikan menjadi 2,46 \%, lalu mengalami penurunan kembali secara signifikan hingga menjadi 1,75 pada elevasi 1.200++ mdpl. Kadar abu dan kadar air pada kopi menunjukkan respon yang berbeda terhadap elevasi. Pada kadar air semakin tinggi elevasi maka semakin banyak kadar air yang terdapat di dalam biji kopi, lain halnya dengan kandungan abu yang menunjukkan respon bahwa semakin tinggi elevasi penanaman kopi maka semakin rendah kadar abu yang dikandung, hal ini dikarenakan kandungan air dan abu selalu berbanding terbalik, sehingga terjadilah perbedaan respon. 


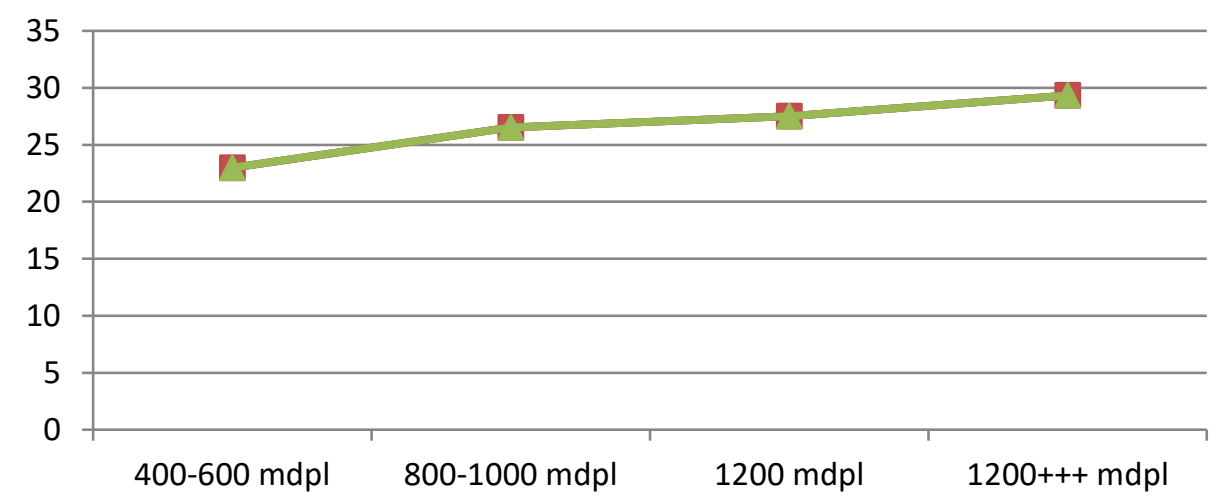

Gambar 2. Grafik kadar antioksidan kopi robusta muria kudus (\%).

Kafein merupakan salah satu produk fitokimia dari kopi, seluruh jenis kopi mengandung kafein dengan kadar yang berbeda-beda. Kafein tergolong metabolit skunder golongan alkaloid heterosiklik yang memiliki fungsi stimulant dan mampu merelaksasikan otot polos terutama bronkus dan jantung (Arizziani, T, 2017). Kadar kafein yang terdapat di dalam biji kopi Robusta antara 1,50-2,72\%, sedangkan setelah melewati penyangraian kadar kafeinnya mencapai 2\% (Widyotomo, S dan Mulato, S. 2007). Kisaran di atas sesuai dengan hasil yang ditunjukkan oleh Tabel 1, yaitu kadar kafein kopi robusta setelah disangrai berkisar antara 1,12-4,36 \% untuk kopi Robusta Muria Kudus. Elevasi memberikan pengaruh terhadap kadar kafein yang dikandung oleh biji kopi hal ini dibuktikan dengan melihat tabel 1 yang menampilkan bahwa setiap elevasi menunjukkan hasil yang berbeda-beda. Elevasi dengan kadar kafein terendah berada pada elevasi 400-600 mdpl, sedangkan elevasi dengan kadar kafein tertinggi pada elevasi 1.200 mdpl.

Berdasarkan Tabel 1, dapat dilihat bahwa elevasi berpengaruh terhadap kadar lemak biji kopi. Elevasi tidak menunjukkan pengaruh berupa peningkatan atau penurunan yang bertahap, melainkan menunjukkan hasil yang berbeda-beda di setiap elevasinya kecuali pada ketinggian 400-600 mdpl dan 800-1.000 mdpl pada kopi Robusta Muria Kudus. Kandungan lemak terendah berada pada elevasi $1.200++$ mdpl yaitu sebesar 9,10 $\%$ dan kandungan lemak tertinggi berada pada elevasi 400-600 mdpl dan 800-1.000 mdpl yaitu sebesar $10,08 \%$.

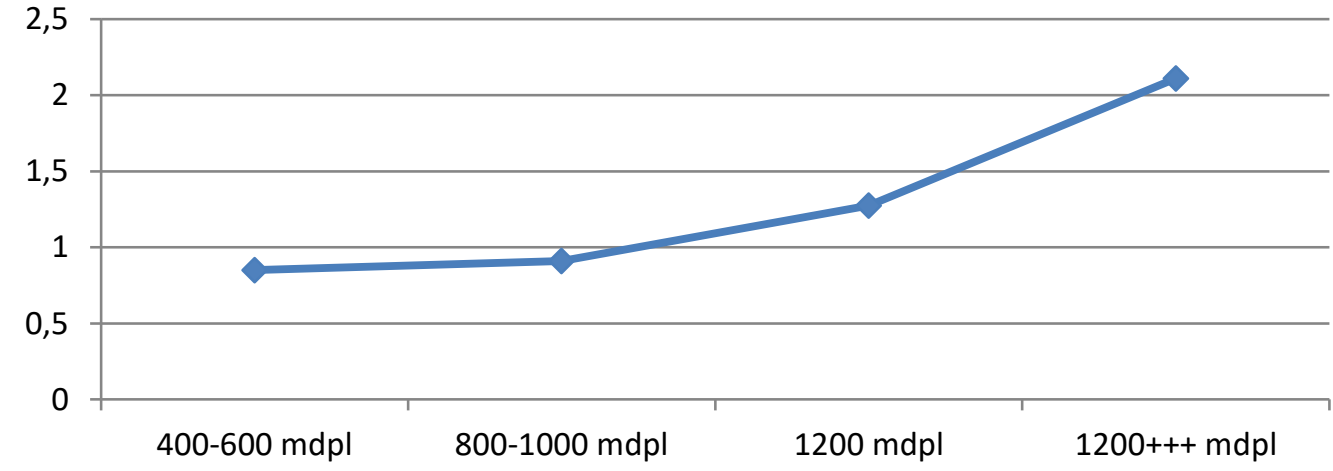

Gambar 3. Grafik Kadar Air kopi Robusta Muria Kudus 


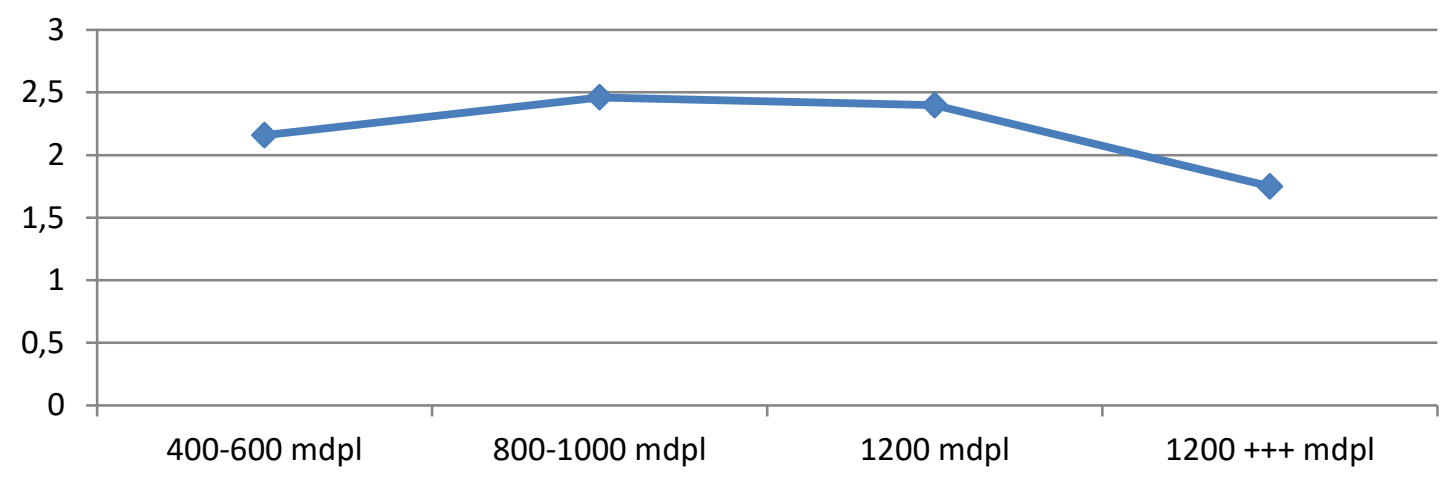

Gambar 4. Grafik Kadar Air abu Robusta Muria Kudus

Aroma marupakan kunci untuk mendefinisikan level kualitas kopi yang diterima konsumen untuk produk kopi. pembentukan aroma kopi yang diinginkan dikaitkan dengan reaksi Maillard, bersama dengan reaksi katalis termal lainnya yang terjadi selama pemanggangan pada suhu biasanya di luar $200^{\circ} \mathrm{C}$ (De Maria, C et al, 1996 dan Maeztu, L et al, 2001). Roasting meningkatkan degradasi trigonelline, sukrosa dan asam amino dalam fraksi (B) dan arabinogalactan dalam fraksi (C). Analisis dari fraksi terisolasi penyangraian menunjukkan bahwa furan tidak hanya terbentuk oleh degradasi sukrosa tetapi juga oleh pirolisis arabinogalaktan. Juga, pirazin tampaknya terutama dibentuk oleh pirolisis asam amino hidroksi dari fraksi (C). Hasil penelitian yang dilakukan oleh De Maria et al. (1996) juga menunjukkan bahwa piridin yang ditemukan dalam kopi panggang tidak secara eksklusif dibentuk oleh degradasi trigonelline tetapi juga oleh pirolisis protein. Pengaruh berbagai variabel dan proses fermentasi kopi pada pembentukan aroma selama penyangraian menyoroti hubungan yang kompleks antara fermentasi kopi dan rasa. Perbaikan kualitas pengolahan kopi kemungkinan besar disebabkan modifikasi komposisi aroma prekusor dalam biji kopi hijau diamati setelah fermentasi. Pada proses ini, ceri kopi yang sudah dipetik, dipilih dan dicuci. Lalu, dimasukkan ke wadah berbahan stainlesssteel dan ditutup rapat, sehingga tidak ada udara (oksigen) yang masuk. Fermentasi dilakukan menggunakan air dan mikroorganisme pada ceri kopi. Proses fermentasi tersebut memecahkan kulit dengan biji kopi. Waktu yang dibutuhkan selama proses fermentasi berlangsung adalah sekitar 18 hingga 24 jam. Sedangkan, untuk pengeringan dibutuhkan waktu sekitar 3 hingga 4 hari sebelum dipindahkan ke 'AfricanDryingBeds' yang akan didiamkan selama 18 hingga 20 hari (Lee. L et al, 2015).

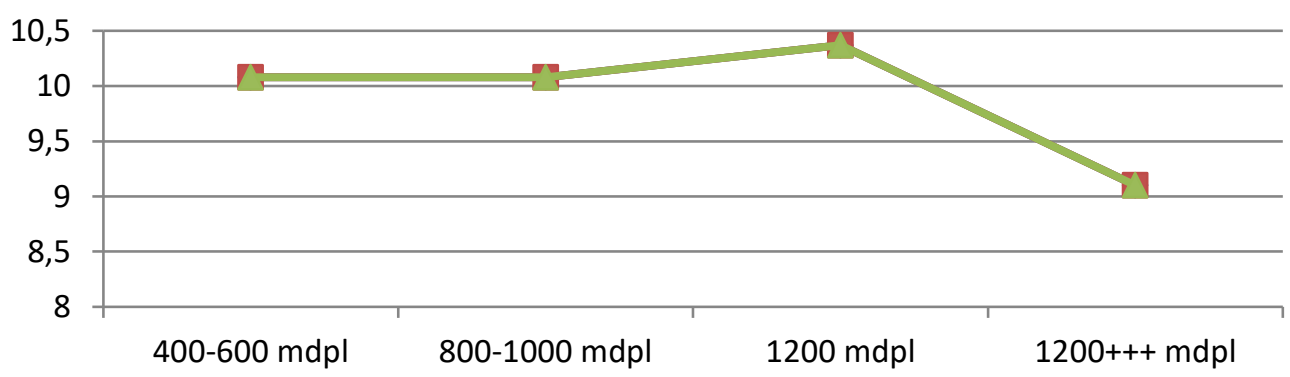

Gambar 5. Grafik Kadar lemak abu Robusta Muria Kudus 


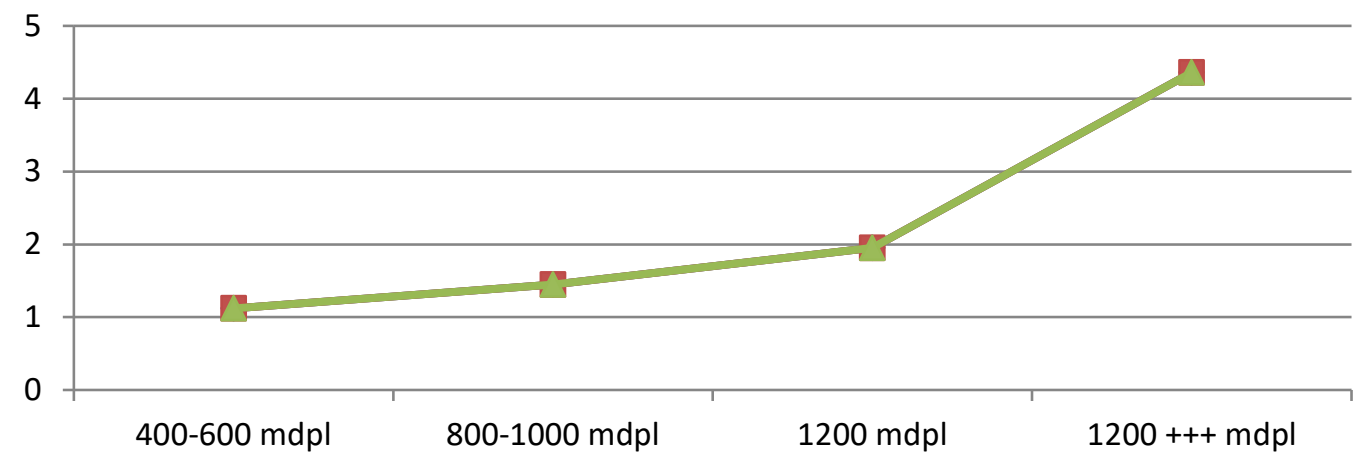

Gambar 6. Grafik Kadar Kafein abu Robusta Muria Kudus

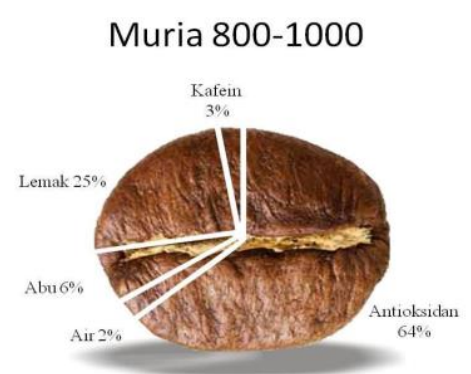

Muria $1200++$

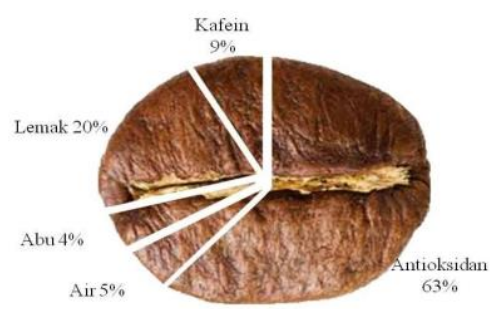

Muria 1200

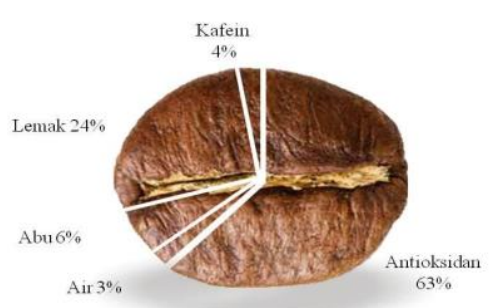

Muria 400-600

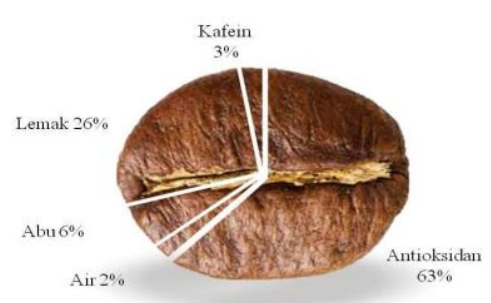

Gambar 7. Hasil uji kandungan sampel kopi muria berdasarkan elevasi. 
Uji Organoleptik. Hasil uji organoleptik menunjukkan hasil yang berbeda-beda pada setiap sampel. Ada sampel kopi muria dari berbagai ketinggian cenderung memiliki rasa yang sama. Pada ketinggian 400 - 1000 mdpl memiliki aftertaste seperti kacangkacangan dan buah-buahan. Sedangkan pada sampel kopi dengan ketinggian $1200++$ mdpl aftertaste seperti kacang tanah dan menyisakan rasa spacy di bibir. Kekentalan (body) pada sampel kopi muria dari berbagai ketinggian sama yakni cair. Aroma setelah diseduh pada masing-masing sampel seperti gula bakar. Semakin rendah ketinggian sampel kopi maka semakit pekat warna sampel kopi muria. Pada ketinggian rentang antara 400 - 1000 mdpl berwarna hitam pekat. Sedangkan sampel pada ketinggian rentang antara $1000-1200++$ mdpl berwarna coklat kehitaman.

Tabel 2. Rata-rata penilaian panelis tentang warna

\begin{tabular}{clccccc}
\hline \multirow{2}{*}{ No } & \multirow{2}{*}{ Sampel } & \multicolumn{5}{c}{ Warna } \\
\cline { 3 - 7 } & & 1 & 2 & 3 & 4 & 5 \\
\hline 1 & Muria 1200++ mdpl & & 1 & 5 & 12 & 7 \\
\hline 2 & Muria 1200 mdpl & & 2 & 3 & 11 & 9 \\
\hline 3 & Muria 800-1000 mdpl & 4 & 21 & & & \\
\hline 4 & Muria 400-600 mdpl & & 6 & 18 & 1 & \\
\hline
\end{tabular}

Keterangan :

$1=$ Sangat hitam

2 = Agak hitam

$3=$ Tidak berbeda

$4=$ Kurang hitam

$5=$ Sangat kurang hitam

Tabel 3. Rata-rata penilaian panelis tentang rasa

\begin{tabular}{ccccccc}
\hline \multirow{2}{*}{ No } & Sampel & 1 & 2 & 3 & 4 & 5 \\
\cline { 2 - 7 } 1 & Muria 1200++ mdpl & 2 & 8 & 3 & 12 & \\
\hline 2 & Muria 1200 mdpl & & & 4 & 13 & 9 \\
\hline 3 & $\begin{array}{c}\text { Muria 800-1000 } \\
\text { mdpl }\end{array}$ & 4 & 15 & 6 & & \\
\hline 4 & $\begin{array}{c}\text { Muria 400-600 } \\
\text { mdpl }\end{array}$ & 8 & 6 & & 11 & \\
\hline
\end{tabular}

Keterangan :

$1=$ Sangat pahit

$2=$ Agak pahit

$3=$ Tidak berbeda

$4=$ Agak kurang pahit

$5=$ Sangat kurang pahit 
Proses roasting merupakan proses penting dalam dunia kopi yakni pengolahan biji kopi menjadi bubuk kopi agar dapat diseduh dan dinikmati oleh masyarakat. Beragam hal menarik dari proses penyangraian biji kopi, seperti level pemanggangan yang akan mempengaruhi cita rasa kopi yang berbeda-beda. Kualitas dan aroma kopi akan terpengaruh sebanyak $30 \%$ bergantung pada proses roasting yang dilakukan. Sebanyak $55 \%$ faktor yang mempengaruhi aroma dan rasa kopi adalah kondisi geografis letak perkebunan, kondisi iklim, ketinggian tanaman, varietas kopi, dan proses paska panen. Sedangkan 15\% pengaruh aroma dan rasa adalah coffee brewing (De Maria, C et al, 1996 dan Maeztu, L et al, 2001). Biji kopi yang telah melalui proses roasting akan mengalami banyak perubahan seperti pengurangan kadar air, perubahan berat dan ukuran hingga perubahan warna.

Tabel 4. Rata-rata penilaian panelis tentang aroma

\begin{tabular}{llrrrrr}
\hline \multirow{2}{*}{ No } & \multirow{2}{*}{ Sampel } & \multicolumn{5}{c}{ Aroma } \\
\cline { 3 - 7 } & & 1 & 2 & 3 & 4 & 5 \\
\hline 1 & Muria 1200++ mdpl & 3 & 12 & 7 & 2 & \\
\hline 2 & Muria 1200 mdpl & 2 & 15 & 3 & 5 & \\
\hline 3 & Muria 800-1000 mdpl & 5 & 10 & 5 & 5 & \\
\hline 4 & Muria 400-600 mdpl & 3 & 9 & 6 & 6 & 1
\end{tabular}

Keterangan:

$1=$ Sangat tajam

2 = Agak tajam

$3=$ Tidak berbeda

4 = Agak kurang tajam

$5=$ Sangat kurang tajam

Kesempurnaan penyangraian kopi dipengaruhi oleh dua faktor utama, yaitu panas dan waktu. Kisaran suhu yang dibutuhkan pada level ringan menghasilkan warna coklat muda adalah $20^{\circ} \mathrm{C}$, tingkat sangkai dengan warna agak coklat dengan suhu $215-245^{\circ} \mathrm{C}$. Proses penyangraian dapat dilakukan secara terbuka maupun tertutup. Derajat penyangraian secara kualitatif dapat dilihat berdasarkan warna kopi yang telah disangrai. Misalnya light roast, medium roast, dan dark roast. Waktu dan suhu yang digunakan saat penyangraian bervariasi menyesuaikan karakteristik dari alat.

Tabel 5. Rata-rata penilaian panelis tentang tekstur

\begin{tabular}{lllcccc}
\hline \multirow{2}{*}{ No } & \multirow{2}{*}{ Sampel } & \multicolumn{5}{c}{ Tekstur } \\
\cline { 3 - 6 } & & 1 & 2 & 3 & 4 & 5 \\
\hline 1 & Muria 1200++ & & & 4 & 2 & 19 \\
\hline 2 & Muria 1200 mdpl & & & 7 & 15 & 3 \\
\hline 3 & Muria 800-1000 mdpl & 8 & 8 & 4 & 4 & 1 \\
\hline 4 & Muria 400-600 mdpl & 6 & 10 & 6 & & 3 \\
\hline
\end{tabular}

Keterangan:

$1=$ Sangat kental

2 = Agak kental

$3=$ Tidak berbeda

4 = Agak kurang kental

$5=$ Sangat kurang kental 


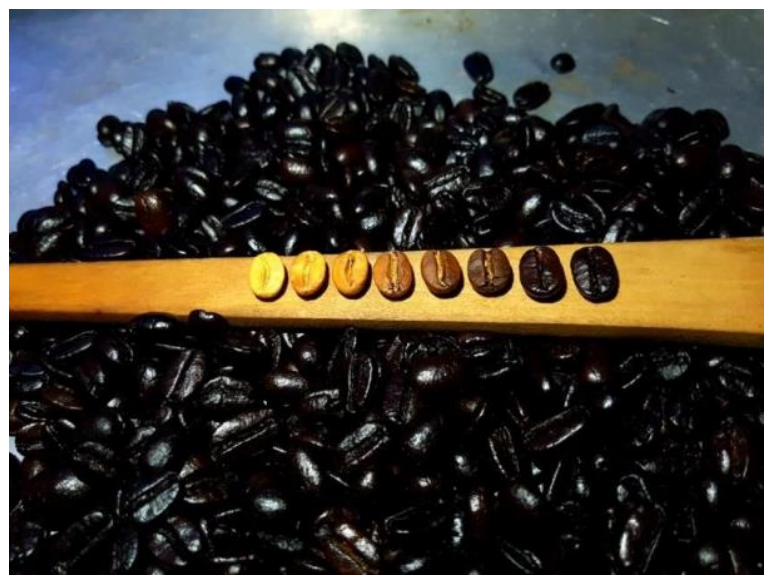

Gambar 8. Perubahan warna pada biji kopi yang telah pelalui proses roasting

Fase yang terjadi pada medium roasting adalah proses caramelyzed. Pada proses ini cenderung membentuk karakter aroma dan rasa sweet pada kopi. Roasted bean mengalami developing aroma dan rasa dari fase sebelumnya (first crack). Rasa dan keasaman yang dihasilkan akan lebih seimbang, kandungan kafein lebih sedikit dan memiliki profil tekstur yang lebih kental daripada light roasting. Secara visual, medium roasting menghasilkan warna coklat gelap (Maulana, 2016). Tingkat kematangan medium roasting yakni biji kopi disangrai pada suhu 220 derajat C. Waktu proses sangrai ditetapkan selama 10 menit dan 5 menit tempering. Tingkat kandungan gula alami sudah mulai sedikit berkaramel dan tingkat keasamannya menurun. Kualitas kopi (Specialy coffee) sangat ideal untuk diroasting pada level ini, karena tahap ini lebih seimbang dan menonjolkan sisi rasa, aroma, dan acidity sepeti origin biji kopi. Medium roasting cocok untuk kopi ekspresso, baik diseduh dengan mokapot maupun mesin ekspresso. Tingkat kandungan kafein yang rendah menghasilkan kopi yang cenderung seimbang antara aroma, keasaman dan menghasilkan banyak rasa.

Light rosting merupakan fase terjadinya proses enzimal yang membentuk karakteristik keasaman (acidity) pada biji kopi. Green bean akan mengalami perubahan warna dari raw (mentah) menuju yellowig (penguningan) lalu browning (pencoklatan) hingga awal frist crack (pecah pertama). Proses pecah pertama ini sendiri merupakan fase yang terjadi karena uap air di dalam biji kopi yang bertemu dengan karbondioksida (CO2) yang memiliki tekanan. Selanjutnya terlepasnya panas pada biji kopi akan terbentuknya glukosa sehingga menimbulkan popping sound (seperti bunyi popcorn). Karakteristik aroma dan rasa kopi di light roast profile akan cenderung toasted grain, ringan, kafein dan keasaman yang dominan dan secara visual. Profil warna biji kopi cenderung coklat terang (Maulana, 2016).

Tingkat kematangan Light roasting yakni biji kopi disangrai pada suhu 200 derajat C. Waktu proses sangrai ditetapkan selama 10 menit dan 5 menit tempering. Tingkat biji kopi berwarna coklat muda, karakternya ringan dari sisi biji. Tidak terdapat lapisan minyak dipermukaan. Level keasamannya lebih tinggi. Tingkat light roasting ini mengandung kafein lebih tinggi dibandingkan dengan kopi yang dark roasting. Light roasting cocok untuk metode seduh tubruk, french press ataupun kopi saring (pour over). Tingkat roasting ini cocok bagi orang yang menyukai rasa kopi mencolok, karena memiliki ciri khas seperti citrusy, earthy, dan buttery. 


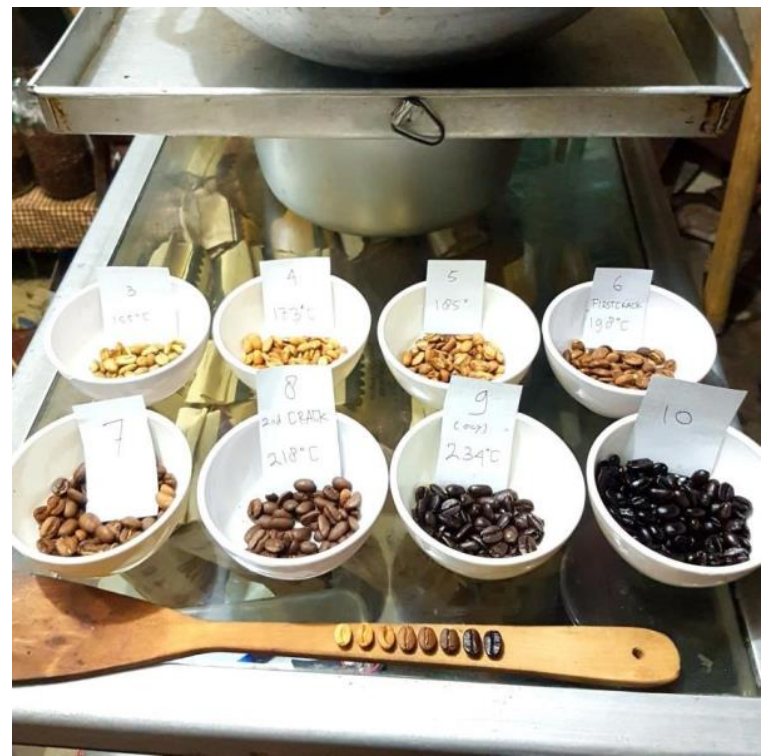

Gambar 9. Perubahan warna pada biji kopi dengan penyangraian pada suhu yang berbeda-beda.

Proses dark roasting pada fase ini biji kopi telah melewati perjalanan pajang yang membawa banyak perubahan. Perubahan tersebut mulai dari berat yang semakin berkurang (ringan), warna yang lebih gelap (almost black) dengan kandungan minyak yang tampak di permukaan biji kopi. Ukuran kopi yang lebih besar dibandingkan dengan kondisi semula saat biji kopi masih mentah (raw green bean). Pada drak roast profile ini terjadi proses carbonyzed yang terjadi pada biji kopi sehingga karakteristik aroma dan rasa kopi umumya akan cenderung pahit, agak gosong, dan kafeinnya paling sedikit. Tingkat kematangan dark roasting yakni biji kopi disangrai pada suhu 230 derajat C. Waktu proses sangrai ditetapkan selama 10 menit dan 5 menit tempering (Nugroho, 2009). Tingkat dark roasting memiliki warna gelap seperti coklat hampir hitam. Lapisan minyak pekat dipermukaan dan dapat terlihat pada permukaan cangkir ketika kopi sudah diseduh. Rasa pahit menjadi lebih menonjol seperti aroma smoky, karakter rasa (flavor) berkurang (Maulana, 2016). Hasil sangrai dark roasting biasa digunakan untuk minuman kopi espresso, cafe-latte, dan cappucino. Bagi yang menyukai kopi dengan kekentalan (body) kopu yang tebal, sangat cocok dengan profil dark roasting. Pemilihan roasting profile dipengaruhi oleh pergeseran selera pasar. Keinginan untuk lebih mengeksplorasi karakteristik aroma dan rasa pada biji kopi yakni profil light roast dan medium roast. Proges positif dengan semakin baiknya proses paska panen yang menghasilkan biji kopi berkualitas juga akan membuat orang berfikir.

\section{SIMPULAN}

Hasil penelitian pada Kopi Robusta Muria Kudus menunjukkan bahwa elevasi mempengaruhi kadar kandungan kimia biji kopi. Semakin tinggi elevasi, kondungan antioksidan, kafein dan kadar airnya terus meningkat, sedangkan pada kadar abu nilai maksimum berada pada ketinggian 800-1.000 mdpl dan kandungan lemak maksimal pada ketinggian $1.200 \mathrm{mdpl}$. Light rostingmembentuk karakteristik keasaman (acidity) pada biji kopi, warna dari raw (mentah) menuju yellowig (penguningan) lalu browning (pencoklatan) hingga awal frist crack (pecah pertama). Karakteristik aroma dan rasa kopi di light roast profile akan cenderung toasted grain, ringan, kafein dan keasaman yang 
dominan dan secara visual. Profil warna biji kopi cenderung coklat terang. Penyangraian tingkat medium cenderung membentuk karakter aroma dan rasa sweet pada kopi dengan rasa dan keasaman yang dihasilkan lebih seimbang, kandungan kafein lebih sedikit dan memiliki profil tekstur yang lebih kental daripada light roasting. Secara visual, medium roasting menghasilkan warna coklat gelap. Proses dark roasting menghasilkan kopi dengan berat lebih ringan, warna yang lebih gelap (almost black) dengan kandungan minyak yang tampak di permukaan biji kopi. Karakteristik aroma dan rasa kopi umumya akan cenderung pahit, agak gosong, dan kafeinnya paling sedikit.

\section{DAFTAR RUJUKAN}

Aak. (1980). Budidaya Tanaman Kopi. Yogyakarta: Yayasan Kanisius.

Agastya, Dewa, P. (2017). Mesin Roasting Biji Kopi Portable Berbasis Mikrokintroler. Skripsi. Yogyakarta: Universitas Sanata Dharma.

Anonim. (2014). Coffee Plant Species: Arabica vs Specialty Robusta. https://www.perfectdailygrind.com/2015/08/coffeeplant-species-arabica-vsspecialty-robusta/. Diakses pada 04 November 2018.

Anonim. (2016). Harga Kopi di Temanggung Merangkak Naik. http://temanggungan.com/harga-kopi-di-temanggungmerangkak-naik/.Diakses pada 03 November 2018.

Arifin, M dan Ariyanto. (2018). Desa Penghasil Kopi Untuk Meningktakan Ekonomi Masyarakat di Desa Damarwulan Kecamatan Keling Kabupaten Jepara. Jurnal ABDIMAS Unmer Malang, 3(1):19-31.

Arrizkiani, T. (2017). Skrining Fitokimia Dan Analisis Kromatografi Lapis Tipis Senyawa Alkaloid dari Berbagai Ekstrak Kopi Robusta (Coffea canephora). Jurnal Kesehatan Bakti Tunas Husada, 17 (2).

Assosiation of Official Analycal Chemistry. (1990). Assosiation of Official Analycal Chemistry (AOAC) Official Method 930.08, Caffeine Content.

Assosiation of Official Analycal Chemistry. (2000). Assosiation of Official Analycal Chemistry (AOAC) Official Method 972.15, Ash Content.

Assosiation of Official Analycal Chemistry. (2005). Assosiation of Official Analycal Chemistry (AOAC) Official Method 963.15, Fat Content.

Avelino, J., Barboza, B., Araya, J.C., Fonseca, C., Davrieux, F., Guyot, B., \& Cilas, C. (2005). Effects of slope exposure, altitude and yield on coffee quality in two altitude terroirs of Costa Rica, Orosi and Santa Maria de Dota. Journal of The Science of Food and Agriculture, 85, 1869-1876

Bejo, A. (2008). C dan AVR Rahasia Kemudahan Bahasa $C$ dalam Mikrokontroler ATMEGA 8535. Yogyakarta: Graha Ilmu.

Bertrand, B., Vaast, P., Alpizar, E., Etienne, H., Davrieux, F., \& Charmentant, P. (2006). Comparison of bean biochemical composition and beverage quality of Arabica hybrids involving Sudanese-Ethiopian origins with traditional varieties at various elevations in Central America. Tree Physiology, 26 : 1239-1248.

Budiman, H., Rahmawati, F., dan Sanjana, F. (2015). Isolasi dan Identifikasi alkaloid pada Biji Kopi Robusta (Coffea robusta Lindl. Ex De Will) dengan Cara Kromatografi Lapis Tipis. Skripsi Program Sarjana. STIKES Muhamadiyah Klaten.

Da-Silva, E.A., Mazzafera, P., Brunini, O., Sakai, E., Arruda, F.B., Mattoso, L.H.C., ... Pires, R.C.M. (2005). The influence of water management and environmental 
conditions on the chemical composition and beverage quality of coffee beans. Brazilian Journal of Plant Physiology, 17(2): 229-238.

De Maria, C et al. (1996). Composition of Green Coffee WaterSoluble Fractions and Identification of Volatiles Formed During Roasting. J. Food Chemistry, 55 (3) : 207-207.

De-Castro, R.D., \& Marraccini, P. (2006). Cytology, biochemistry and molecular changes during coffee fruit development. Brazilian Journal of Plant Physiology,18(1), 175-199.

Dewi, L., Hastuti, S., dan Silana, L. TT. (2010)Aktifitas Antioksidan, Kadar Fenolik Total dan Kadar Kafein pada Fermentasi Kombu Kopi Robusta dalam Berbagai Konsentrasi Gula. Makalah Seminar Nasional Mikrobiologi-Fakultas Biolog UKSW Slatiga.

Direktorat Jenderal Perkebunan. (2016). Statistik Perkebunan Indonesia. Jakarta: Direktorat Jenderal Perkebunan Kementerian Pertanian.

Edvan, B,. Edison, R,. dan Same, M. (2016). Pengaruh Jenis dan Lama Penyangraian pada Mutu Kopi Robusta (Coffea robusta). Jurnal Agro Industri Perkebunan, 4 (1): 31-40.

Ermawati, R., Arief, R.W., \& Slamet. (2008). Teknologi budidaya kopi poliklonal (p.17). Bandar Lampung: Balai Pengkajian Teknologi Pertanian Lampung.

Lee, L et al. (2015). Coffee Fermentation and Flavor-an Intricate and Delicate Relationship. J. Food Chemistry, 185(2015): 182 - 191.

Maeztu, L et al. (2001). Characterization Of Espresso Coffee Aroma by Static Headspace GC-MS And Sensory Flavor Profile. J. Agric. Food Chem, 49 (11): 54375444.

Maulana, M. (2016). Analisis Kematangan Kopi Sangrai Menggunakan Pemroresan Citra Termografi dalam Rangka Pengontrolan Mutu Kopi Sangrai Secara Otomatis. Skripsi. Jurusan Teknik Mesin Fakultas Teknik Universitas Lampung.

Naido, N et al. (2011). Cholesterol-Raising Diterpenes In Types Of Coffee Commonly Consumed In Singapore, Indonesia And India And Associations With Blood Lipids: A Survey And Cross Sectional Study. Nutrition Journal, 10: 10-48.

Najiyanti, S dan Danarti. (2004). Budidaya Tanaman Kopi dan Penanganan Pasca Panen. Jakarta: Penebar Swadaya.

Nugroho, J, et al. (2009). Pengaruh Suhu dan Lama Penyangraian terhadap Sifat FisikMekanis Biji Kopi Robusta. Makalah Bidang Teknik Produk Pangan.

Seminar Nasional dan Gelar Teknologi PERTETA.

Pusat Penelitian Kopi dan Kakao Indonesia. (2008). Klon-klon unggul kopi robusta dan beberapa pilihan komposisi klon berdasarkan kondisi lingkungan. Jember : Pusat Penelitian Kopi dan Kakao Indonesia.

Rahardjo, P. (2012). Panduan Budidaya dan Perolehan Kopu Arabika dan Robusta. Jakarta: Penebar Swadaya.

Rahayu. (2011). Evaluasi Daya Dukung Lahan Untuk Tanaman Pangan Pada Lahan Perkebunan Tembakau Rakyat Di Lereng Timur Gunung Sindoro. Jurnal Ilmu Tanah dan Agroklimatologi, 8 (2): 67-72.

Santos, C dan Hernandez, T. (2006). Coffee Biotechnology. Brazilian Journal of Plant Physiology. 18 (1): 217-227.

Setiawan, H. (2017). Pengelolaan Lanskap Untuk Mengurangi Laju Erosi Lahan Tembakau Di Kawasan Timur Lereng. Tidak diterbitkan. Surakarta: UNS. 
Soetriono. (2009). Strategi peningkatan daya saing agribisnis kopi robusta dengan model daya saing tree five. Paper presented at Seminar Nasional Peningkatan Daya Saing Agribisnis Berorientasi Kesejahteraan Petani 14 Oktober 2009. Bogor

Suhartini, Y dan Budiati, L. (2015). Evaluasi Rehabilitasi Hutan dan Lahan (RHL) di Daerah Aliran Sungai (DAS) Juwana pada Kawasan Gunung Muria Kabupaten Pati. Jurnal Pembangunan Wilayah dan Kota, 11(1): 117128.

Syah, H,. Yusmanizar, dan Maulana, O. (2013). Karakteristik Fisik Bubuk Kopi Arabika Hasil Penggilingan Mekanis Dengan Penambahan Jagung dan Beras Ketan. Jurnal Teknologi dan Industri Pertanian Indonesia, 5(1) : 32-37.

Towaha, J et al. (2014). Pengaruh Elevasi dan Pengolahan Terhadap Kandungan Kimia dan Citarasa Kopi Robusta Lampung. J.TIDP, 1 (1): 57-62.

Widjanarko. (2016). Modal Sosial Masyarakat Desa Rahtawu: Studi Kasus Pelestarian Hutan Muria Di Kabupaten Kudus. Jurnal Masyarakat dan Budaya,18 (1): 109 120.

Widjarnoko, M dan Wismar'ein, D. (2011). Identifikasi Sosial Potensi Ekowisata Berbasis Peran Masyarakat Lokal. Jurnal Psikologi Undip, 9 (1): 33- 39.

Widodo, Wahyu Eko, et al. (2015). Kinerja Alsin Sangrai Kopi Tipe Fluidisasi dan Uji Kualitas Kopi Sangrai. Jurnal Teknologi Pertanian, 16 (2): 117-126.

Widyotomo, S dan Mulato, S. (2007). Kafein: Senyawa Penting pada Biji Kopi. Warta Pusat Penelitian Kopi dan Kakao Indonesia, 23(1):44-50. 